\title{
Effect of tin-chloride pretreatment on bond strength of two adhesive systems to dentin
}

\author{
Anne Peutzfeldt • Tamara Koch • Carolina Ganss • \\ Simon Flury • Adrian Lussi
}

Received: 21 November 2012 / Accepted: 25 March 2013/Published online: 17 April 2013

(C) Springer-Verlag Berlin Heidelberg 2013

\begin{abstract}
Objectives To determine the effect on resin composite-todentin bond strength of incorporation of an acidic tin-chloride pretreatment in two adhesive systems.

Materials and methods Human molars were ground to expose mid-coronal dentin. For microtensile bond strength ( $\mu$ TBS) testing, dentin was treated with Optibond FL or Clearfil SE according to one of six protocols ( $n=22$ /group). Group 1: Phosphoric acid etching, Optibond FL Prime, Optibond FL Adhesive (manufacturer's instructions; control); Group 2: Tin-chloride pretreatment, Optibond FL Prime, Optibond FL Adhesive; Group 3: Phosphoric acid etching, tin-chloride pretreatment, Optibond FL Prime, Optibond FL Adhesive; Group 4: Clearfil SE Primer, Clearfil SE Bond (manufacturer's instructions; control); Group 5: Phosphoric acid etching, Clearfil SE Primer, Clearfil SE Bond; and Group 6: Tin-chloride pretreatment, Clearfil SE Primer, Clearfil SE Bond. The molars were then built up with resin composite (Clearfil Majesty Esthetic).
\end{abstract}

\footnotetext{
A. Peutzfeldt $(\bowtie) \cdot T$. Koch $\cdot$ S. Flury $\cdot$ A. Lussi

Department of Preventive, Restorative and Pediatric Dentistry, School of Dental Medicine, University of Bern, Freiburgstrasse 7, CH-3010 Bern, Switzerland

e-mail: anne.peutzfeldt@zmk.unibe.ch

T. Koch

e-mail: tamara.koch@zmk.unibe.ch

S. Flury

e-mail: simon.flury@zmk.unibe.ch

A. Lussi

e-mail: adrian.lussi@zmk.unibe.ch

C. Ganss

Department of Conservative and Preventive Dentistry, Dental

Clinic of the Justus Liebig University, Schlangenzahl 14,

35392 Giessen, Germany

e-mail: carolina.ganss@dentist.med.uni-giessen.de
}

After storage ( 1 week, $100 \%$ humidity, $37^{\circ} \mathrm{C}$ ) the $\mu$ TBS was measured and failure mode was determined. Additionally, pretreated dentin surfaces were evaluated using SEM and EDX. The $\mu$ TBS results were analyzed statistically by a Welch Two Sample t-test and a Kruskal-Wallis test followed by exact Wilcoxon rank sum tests with Bonferroni-Holm adjustment for multiple testing ( $\alpha=0.05$ ).

Results When Optibond FL was used, partial or total replacement of phosphoric acid with tin-chloride decreased $\mu$ TBS significantly. In contrast, when Clearfil SE was used, inclusion of a tin-chloride pretreatment in the adhesive procedure increased $\mu$ TBS significantly.

Conclusions Tin-chloride pretreatment had a beneficial influence on the bond promoting capacity of the MDPcontaining adhesive system Clearfil SE.

Keywords Adhesion $\cdot$ Etch-and-rinse adhesive $\cdot$ Resin composite $\cdot$ Self-etch adhesive $\cdot$ Stannous chloride

\section{Introduction}

Tin-containing toothpastes have been on the market for decades because of its proven plaque- and gingivitis-reducing effect [1-4]. More recently, tin-containing toothpastes and mouth rinses have proved efficient in reducing erosive wear in enamel and dentin [5-9].

On sound enamel surfaces, tin is mainly deposited as a precipitation on the surface whereas on eroded surfaces, it is mainly incorporated into enamel [10]. Likewise for dentin, tin is deposited or incorporated to various extents in mineralized and demineralized tissue [11]. A recent study investigated the effect of a tin-containing fluoride mouth rinse on the bond of resin composite for erosively demineralized dentin mediated by the two-step self-etch adhesive system Clearfil 
SE Bond known to contain 10-methacryloyloxydecyl dihydrogen phosphate (MDP), an acidic phosphate monomer. Inclusion of the tin-containing fluoride mouth rinse in the cyclic de- and remineralization procedure increased the bond of the resin composite to the erosively demineralized dentin and did so to a significantly higher degree than did inclusion of a sodium fluoride solution [12]. This is of importance since erosive tooth wear is a condition that is becoming more and more common, and erosive wear is therefore becoming an increasingly significant factor to consider in the management of the dentition [13]. The superior efficacy of the tin-containing fluoride mouth rinse over the sodium fluoride solution was explained by the fact that tin incorporated in the fully demineralized organic matrix [11], via various reaction mechanisms, increases accessibility of the adhesive [12]. Provided that the demineralized organic matrix had been continually removed with collagenase during the remineralization phase of the cyclic de- and remineralization procedure, as it happens in vivo, the study also found inclusion of the tin-containing fluoride mouth rinse to result in an overall increased mineral content and in a bond strength to erosively demineralized dentin that was even higher than the bond strength to sound dentin [12]. It remains to be clarified whether the high bond strength was caused by the amount of mineral, by adhesion to tinsupported hydroxyapatite being superior to adhesion to "normal" hydroxyapatite, or by modification of the collagen rendering it more amenable for the adhesive.

Encouraged by the positive effect of the tin-containing fluoride mouth rinse on the resin composite bond to erosively demineralized dentin, the aim of the present study was to incorporate an acidic tin-chloride pretreament into the adhesive procedure of two adhesive systems, one system that contained MDP and one system that did not contain MDP, and to determine the effect on the strength of the bond between resin composite and sound, non-demineralized dentin. The null hypothesis was that there would be no effect on bond strength of the tin-chloride pretreatment procedure.

Additionally, dentin surfaces subjected to the various pretreatments were evaluated by scanning electron microscopy (SEM) and energy dispersive X-ray spectroscopy (EDX).

\section{Materials and methods}

Preparation of dentin specimens

Sound, extracted human third molars were cleaned under tap water and stored in $0.5 \%$ chloramine solution at $4{ }^{\circ} \mathrm{C}$ until use. Before extraction, the patients had been informed about the use of their teeth for research purposes and verbal consent had been obtained. The molars were embedded in circular molds with self-curing acrylic resin (Paladur, Heraeus Kulzer $\mathrm{GmbH}$, Hanau, Germany) and ground on a grinding machine with silicon carbide $(\mathrm{SiC})$ paper grit \#320 (Struers LaboPol21 , Struers, Ballerup, Denmark) until the entire surface was in mid-coronal dentin. The dentin surfaces were air-dried and carefully checked for absence of enamel. Finally, all molars were ground with $\mathrm{SiC}$ paper grit \#500 (Struers LaboPol-21, Struers), using a new $\mathrm{SiC}$ paper after the grinding of eight molars. A total of 150 extracted human third molars was used, i.e. 25 molars in each of six groups that underwent one of six pretreatment procedures: 22 molars for microtensile bond strength ( $\mu$ TBS) measurements and three molars for SEM and EDX evaluation. The materials used and the pretreatment procedures are listed in Table 1. For the SEM and EDX evaluation, the pretreatments did not involve application of Optibond FL Prime and Adhesive or Clearfil SE Bond and thus comprised the following steps from Table 1: Group 1 and 2: steps 1-3, Group 3: steps 1-6, Group 4: steps 1-2, and Groups 5 and 6: steps $1-5$.

\section{$\mu$ TBS measurement and failure mode determination}

Following the pretreatment procedure, the molars for $\mu$ TBS testing were built up in two layers of $2 \mathrm{~mm}$ each with a resin composite (Clearfil Majesty Esthetic, Kuraray, Okayama, Japan; shade A4, Lot No. 0005HA). Each layer of resin composite was light-cured for $20 \mathrm{~s}$ with an LED lightcuring unit (Bluephase Polywave in "High" power mode, Ivoclar Vivadent, Schaan, Liechtenstein). This light-curing unit was also used to cure the adhesive systems in accordance with Table 1 . Light power density was verified to be at least $1,000 \mathrm{~mW} / \mathrm{cm}^{2}$ at the beginning and end of each day of specimen preparation with a radiometer (Demetron Curing Radiometer Model 1000, Demetron Research Corporation, Danbury, CT, USA). The restored molars were kept for 1 week at $100 \%$ humidity and $37^{\circ} \mathrm{C}$.

After storage, the molars were sectioned with an electronically programmable diamond saw under water-cooling (Struers Accutom-5, Struers) perpendicularly to the adhesive interface in both $\mathrm{x}$ and $\mathrm{y}$ directions to obtain nine beams from the most central part of each molar. Four beams per molar were randomly selected for measurement of $\mu \mathrm{TBS}$. In order to calculate the bonding surface (BSU $\left(\mathrm{mm}^{2}\right)$ ) of each beam, the width and breadth were measured using a digital caliper with an accuracy of $0.001 \mathrm{~mm}$ (Mitutoyo IP 65, Kawasaki, Japan). The beams were then fixed by their ends to notched Ciucchi's jigs mounted in a universal testing machine (Syndicad TC550, Syndicad Dental Research, Munich, Germany) with a low viscosity resin (Optibond Adhesive). The beams were stressed in tension at a crosshead speed of $1.0 \mathrm{~mm} / \mathrm{min}$ until fracture and the maximum force $\left(\mathrm{F}_{\max }(\mathrm{N})\right)$ was recorded. The $\mu \mathrm{TBS}$ values (MPa) were calculated according to the formula $\mu \mathrm{TBS}=\mathrm{F}_{\max } / \mathrm{BSU}$. 
Table 1 Materials used and pretreatment procedures of dentin

\begin{tabular}{|c|c|c|c|c|c|c|}
\hline & Group 1 & Group 2 & Group 3 & Group 4 & Group 5 & Group 6 \\
\hline Step1 & $\begin{array}{l}35 \% \mathrm{H}_{3} \mathrm{PO}_{4}{ }^{\mathrm{a}} \\
15 \mathrm{~s}\end{array}$ & $\begin{array}{l}35 \% \mathrm{SnCl}_{2}{ }^{\mathrm{b}} \\
15 \mathrm{~s}\end{array}$ & $\begin{array}{l}35 \% \mathrm{H}_{3} \mathrm{PO}_{4}{ }^{\mathrm{a}} \\
7 \mathrm{~s}\end{array}$ & $\begin{array}{l}\text { Clearfil SE Primer } \\
15 \mathrm{~s}\end{array}$ & $\begin{array}{l}35 \% \mathrm{H}_{3} \mathrm{PO}_{4}{ }^{\mathrm{a}} \\
15 \mathrm{~s}\end{array}$ & $\begin{array}{l}35 \% \mathrm{SnCl}_{2}{ }^{\mathrm{b}} \\
15 \mathrm{~s}\end{array}$ \\
\hline Step 2 & Water rinse $15 \mathrm{~s}$ & Water rinse $15 \mathrm{~s}$ & Water rinse $15 \mathrm{~s}$ & Gently blow dry & Water rinse $15 \mathrm{~s}$ & Water rinse $15 \mathrm{~s}$ \\
\hline Step 3 & Gently blow dry & Gently blow dry & Gently blow dry & Clearfil SE Bond ${ }^{\mathrm{f}}$ & Gently blow dry & Gently blow dry \\
\hline Step 4 & $\begin{array}{l}\text { Optibond FL Prime }^{\mathrm{c}} \\
\text { scrubbing } 15 \mathrm{~s}\end{array}$ & $\begin{array}{l}\text { Optibond FL Prime }^{\mathrm{c}} \\
\text { scrubbing } 15 \mathrm{~s}\end{array}$ & $35 \% \mathrm{SnCl}_{2}{ }^{\mathrm{b}} 7 \mathrm{~s}$ & Gently blow dry & $\begin{array}{l}\text { Clearfil SE } \\
\text { Primer }^{\mathrm{e}} 15 \mathrm{~s}\end{array}$ & $\begin{array}{l}\text { Clearfil SE } \\
\text { Primer }^{\mathrm{e}} 15 \mathrm{~s}\end{array}$ \\
\hline Step 5 & Gently blow dry & Gently blow dry & Water rinse $15 \mathrm{~s}$ & Light-cure $10 \mathrm{~s}$ & Gently blow dry & Gently blow dry \\
\hline Step 6 & $\begin{array}{l}\text { Optibond FL } \\
\text { Adhesive }^{\mathrm{d}}\end{array}$ & $\begin{array}{l}\text { Optibond FL } \\
\text { Adhesive }^{\mathrm{d}}\end{array}$ & Gently blow dry & & Clearfil SE Bond ${ }^{\mathrm{f}}$ & Clearfil SE Bond ${ }^{\mathrm{f}}$ \\
\hline Step 7 & Gently blow dry & Gently blow dry & $\begin{array}{l}\text { Optibond FL Prime } \\
\text { scrubbing } 15 \mathrm{~s}\end{array}$ & & Gently blow dry & Gently blow dry \\
\hline Step 8 & Light-cure $10 \mathrm{~s}$ & Light-cure $10 \mathrm{~s}$ & Gently blow dry & & Light-cure $10 \mathrm{~s}$ & Light-cure $10 \mathrm{~s}$ \\
\hline Step 9 & & & $\begin{array}{l}\text { Optibond FL } \\
\text { Adhesive }^{\mathrm{d}}\end{array}$ & & & \\
\hline Step 10 & & & Gently blow dry & & & \\
\hline Step 11 & & & Light-cure $10 \mathrm{~s}$ & & & \\
\hline
\end{tabular}

a $35 \%$ Phosphoric acid $\left(\mathrm{H}_{3} \mathrm{PO}_{4} ; \mathrm{pH}<1\right)$ diluted from $85 \%$ ortho-phosphoric acid (Lot No. 420613/1), Fluka Chemika, Buchs, Switzerland

b $35 \%$ Tin-chloride $\left(\mathrm{SnCl}_{2} ; \mathrm{pH}<1\right)$, Gaba International, Therwil, Switzerland

${ }^{\mathrm{c}}$ Optibond FL Prime (Lot No. 3707007), Kerr, Bioggio, Switzerland

${ }^{\mathrm{d}}$ Optibond FL Adhesive (Lot No. 3589423), Kerr, Bioggio, Switzerland

${ }^{\mathrm{e}}$ Clearfil SE Primer (Lot No. 01077A), Kuraray, Okayama, Japan. Please note that the application time was $15 \mathrm{~s}$ and not $20 \mathrm{~s}$ as recommended by the manufacturer.

${ }^{\mathrm{f}}$ Clearfil SE Bond (Lot No. 01610A), Kuraray, Okayama, Japan

The failure mode of each beam was stereomicroscopically determined at 45× magnification (Leica ZOOM 2000, Leica, Buffalo, NY, USA) and classified into one of the five following categories: (1) cohesive failure in dentin, (2) adhesive failure at the dentin - adhesive interface, (3) adhesive failure at the adhesive - resin composite interface, (4) mixed adhesive failure (failure modes 2 and 3), and (5) cohesive failure in resin composite.

\section{SEM and EDX evaluation of dentin surfaces}

The three molars from each group were dehydrated in a desiccator for at least five days and then sputter-coated with gold (JFC-1200 fine coater, Jeol, Tokyo, Japan; 60 s, 40 mA). The dentin surfaces were evaluated under an SEM (JSM-6510, Jeol, Tokyo, Japan) equipped with a Silicon Drift Droplet Detector (X-Flash Detector 410-M, Bruker Nano GmbH, Berlin, Germany). For EDX, the acceleration voltage was set to $15 \mathrm{kV}$ and EDX spectra were collected using count rates $\sim 1$ kcps. Count rates remained constant during the measurements, indicating that neither contamination nor loss of mass occurred. The magnification was $2,000 \times$ representing an area of $60 \mu \mathrm{m} \times 45 \mu \mathrm{m}$ for analysis. In addition, micrographs of $5,000 \times$ magnifications were made for the structural investigation of the treated surfaces.
Statistical analysis of $\mu$ TBS values

Out of the four $\mu$ TBS values obtained per molar, a mean $\mu$ TBS value was calculated. Therefore, $22 \mu$ TBS values per group (one mean $\mu$ TBS value per molar) were used for statistical analysis. A Welch Two Sample t-test was applied to test for an effect of adhesive system, and a Kruskal-Wallis test was applied to the results of each adhesive system separately to test for an effect of pretreatment. In case of a statistically significant effect, these tests were followed by exact Wilcoxon rank sum tests and Bonferroni-Holm adjustment for multiple testing. The main statistical analysis was performed with R version 2.14.1 (The R Foundation for Statistical Computing, Vienna, Austria; www.r-project.org). The level of significance was set at $\alpha=0.05$.

\section{Results}

$\mu$ TBS measurement and failure mode determination

The $\mu$ TBS values are shown in Fig. 1. There was a statistically significant effect of adhesive system and a statistically significant effect of pretreatment for both adhesive systems. The 
results of the subsequent exact Wilcoxon rank sum tests are presented in Table 2.

With regard to the effect of adhesive system, there was no significant difference in $\mu$ TBS when the two adhesive systems had been used according to the manufacturers' instructions (Groups 1: 33.3 (5.2) MPa and Group 4: 30.2 (5.4) $\mathrm{MPa})$. Addition of either a phosphoric acid etching step (Group 5: 31.3 (8.7) MPa) or a tin-chloride application step (Group 6: 34.9 (7.2) MPa) prior to application of Clearfil SE resulted in $\mu$ TBS values that also did not differ statistically from the Optibond FL control group (Group 1: 33.3 (5.2) $\mathrm{MPa}$ ). When phosphoric acid etching had been replaced by tin-chloride application, Optibond FL (Group 2: 16.6 (6.8) $\mathrm{MPa})$ resulted in a $\mu$ TBS value that was significantly lower than the $\mu$ TBS values obtained with any of the three Clearfil SE groups (Groups 4-6). Finally, a pretreatment with first phosphoric acid and then tin-chloride prior to application of Optibond FL (Group 3: $26.4(6.1) \mathrm{MPa}$ ) resulted in a $\mu \mathrm{TBS}$ value that did not differ from that of the Clearfil SE control group (Group 4: 30.2 (5.4) MPa), but which was significantly lower that the $\mu$ TBS value obtained when Clearfil SE had been preceeded by application of phosphoric acid (Group 5: 31.3 (8.7) MPa) or tin-chloride (Group 6: 34.9 (7.2) MPa).

With regard to the effect of pretreatment, all three $\mu$ TBS values obtained with Optibond FL (Groups 1-3) varied from each other with statistical significance. The significantly highest $\mu$ TBS value was obtained when the dentin had been etched with phosphoric acid according to manufacturer's instructions (Group 1: 33.3 (5.2) $\mathrm{MPa}$ ), and the lowest $\mu \mathrm{TBS}$ value was obtained when phosphoric acid had been replaced by tin-chloride (Group 2: 16.6 (6.8) MPa). The combined phosphoric acid etching - tin-chloride pretreatment (Group 3: 26.4 (6.1) $\mathrm{MPa}$ ) yielded an intermediary $\mu \mathrm{TBS}$ value. Whereas an additional pretreatment in the form of phosphoric acid (Group 5: 31.3 (8.7) $\mathrm{MPa}$ ) did not significantly increase the $\mu \mathrm{TBS}$ value of Clearfil SE compared to the control (Group 4: 30.2 (5.4) MPa), pretreatment with tin-chloride (Group 6: 34.9 (7.2) MPa) did result in a significantly higher $\mu$ TBS value.

The distribution of failure modes is shown in Table 3. The predominant failure mode was cohesive failure in the resin composite for all groups except Group $2\left(\mathrm{SnCl}_{2}+\right.$ Optibond FL), which presented a majority of adhesive failures at the dentin - adhesive interface. The second most common failure mode in all groups was mixed adhesive failure, and only very few cohesive failures in dentin were observed.

\section{SEM and EDX evaluation of dentin surfaces}

SEM evaluation revealed quite a similar dentin surface for all three molars in each group. Representative micrographs are shown in Fig. 2. The dentin surface that had been ground but not subjected to any pretreatment (Fig. 2A) showed parallel grooves resulting from the grinding procedure and was covered entirely with a smear layer. Phosphoric acid
Fig. 1 Microtensile bond strength values $(\mathrm{MPa})$ of the groups tested (median, lower and upper quartile, as well as lowest value still within $1.5 \times$ the interquartile range of the lower quartile and the highest value still within $1.5 \mathrm{x}$ the interquartile range of the upper quartile)

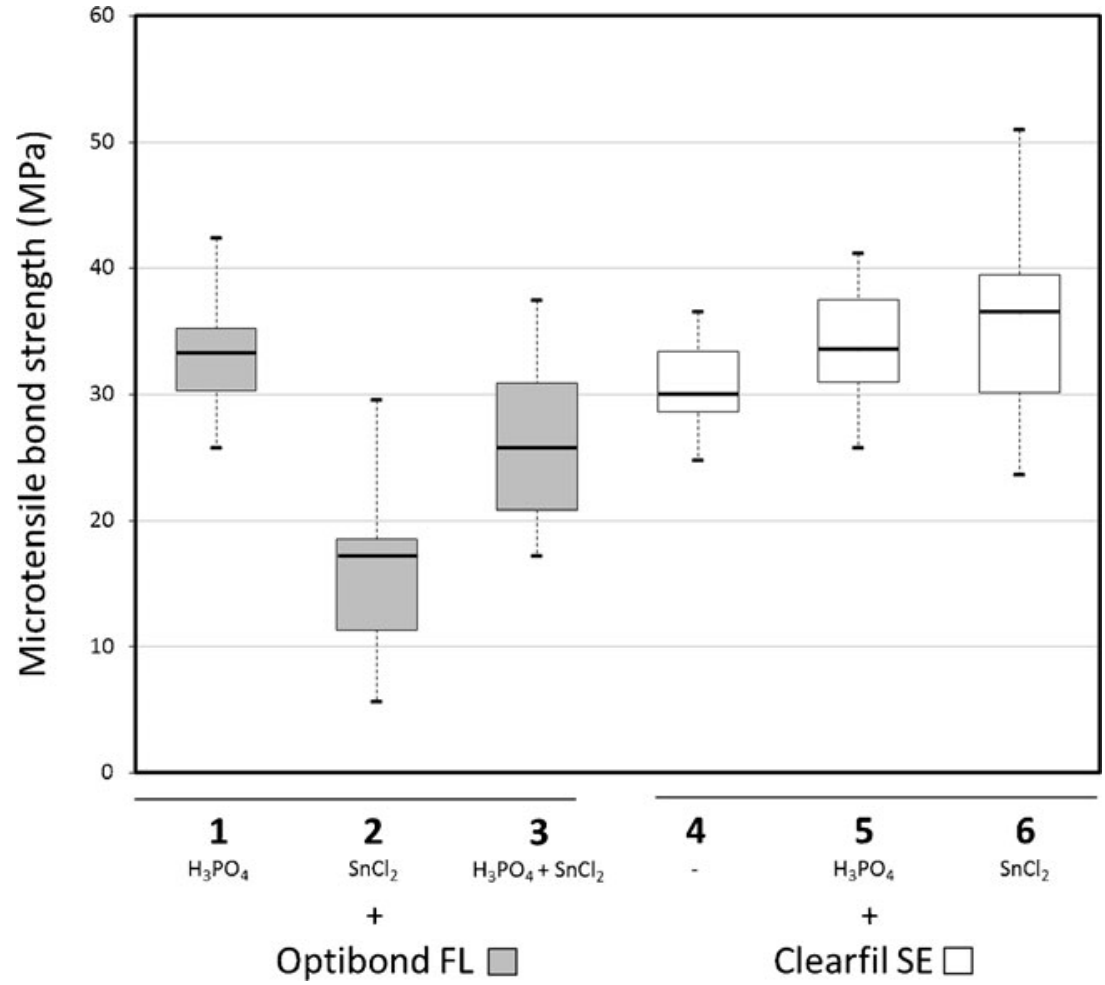


Table 2 Comparison of microtensile bond strength values by Wilcoxon rank sum tests

\begin{tabular}{llllll}
\hline & $\begin{array}{l}\text { Group 2 }\left(\mathrm{SnCl}_{2}+\right. \\
\text { Optibond FL })\end{array}$ & $\begin{array}{l}\text { Group 3 }\left(\mathrm{H}_{3} \mathrm{PO}_{4}+\mathrm{SnCl}_{2}+\right. \\
\text { Optibond FL) }\end{array}$ & $\begin{array}{l}\text { Group 4 } \\
\text { (Clearfil SE) }\end{array}$ & $\begin{array}{l}\mathrm{Group}_{\text {Clearfil SE) }}\left(\mathrm{H}_{3} \mathrm{PO}_{4}+\right. \\
\text { Clearfil SE) }\end{array}$ \\
\hline Group 1 $\left(\mathrm{H}_{3} \mathrm{PO}_{4}+\right.$ Optibond FL) & $\mathrm{P}<0.001$ & $\mathrm{P}<0.005$ & n.s. & n.s. & n.s. \\
Group 2 & - & $\mathrm{P}<0.001$ & $\mathrm{P}<0.001$ & $\mathrm{P}<0.001$ & $\mathrm{P}<0.001$ \\
Group 3 & - & - & n.s. & $\mathrm{P}<0.005$ & $\mathrm{P}<0.001$ \\
Group 4 & - & - & - & n.s. & $\mathrm{P}<0.05$ \\
Group 5 & - & - & - & - & n.s. \\
\hline
\end{tabular}

n.s. $=$ not significant

etching (Group 1) led to complete removal of the smear layer and smear plugs, thus exposing the dentinal tubules (Fig. 2B). Likewise, pretreatment with tin-chloride (Group 2) removed the smear layer and opened the tubules, but peritubular dentin was apparent, as were precipitations in the intertubular areas (Fig. 2C). Phosphoric acid etching followed by tin-chloride treatment (Group 3) resulted in an intermediary situation in that the peritubular dentin was now absent, but precipitations were present (Fig. 2D). Pretreatment with the Clearfil SE Primer (Group 4) led to partial removal of the smear layer, leaving a very thin layer as well as remnants of smear plugs (Fig. 2E). When Clearfil SE Primer application had been preceeded by phosphoric acid etching (Group 5), the results were similar to those in Group 1, i.e. complete removal of the smear layer and fully opened tubules (Fig. 2F). Finally, when Clearfil SE Primer application had been preceeded by tin-chloride treatment (Group 6), the smear layer and smear plugs had been more effectively removed than following only application of Clearfil SE Primer and the dentin surface was covered with precipitates (Fig. 2G).

The EDX spectra revealed distinct differences between groups. Phosphoric acid etching (Group 1) led to demineralization of the dentin surface and showed only small peaks for $\mathrm{Ca}$ and $\mathrm{P}$ (Fig. 3B). In contrast, pretreatment with tin-chloride (Group 2) removed much less $\mathrm{Ca}$ and $\mathrm{P}$ displaying distinct peaks for $\mathrm{Ca}$ and P (Fig. 3C), and tin was clearly detectable. The short phosphoric acid etching followed by a short tin-chloride pretreatment (Group 3) showed an intermediary result with respect to $\mathrm{Ca}$ and $\mathrm{P}$, but led to a relatively high content of tin (Fig. 3D). Pretreatment with the Clearfil SE Primer (Group 4, Fig. 3E) led to much less demineralization that did phosphoric acid etching and resulted in a mineral content similar to that of surfaces pretreated with tinchloride (Fig. 3C). When Clearfil SE Primer application had been preceeded by phosphoric acid etching (Group 5, Fig. 3F), the degree of demineralization resembled that of the combined phosphoric acid etching - tin-chloride pretreatment of Group 3. Finally, when Clearfil SE Primer application was preceeded by tin-chloride treatment (Group 6), distinct tin peaks were apparent (Fig. 3G).

\section{Discussion}

Optibond FL, generally considered the gold standard of threestep etch-and-rinse adhesive systems, was used with three different pretreatments. The highest bond strength to dentin with this adhesive was obtained when pretreatment of dentin had been sought through a $15 \mathrm{~s}$ application of phosphoric acid i.e. when Optibond FL had been used according to the manufacturer's instructions. As the SEM micrographs indicated and the EDX results proved, application of phosphoric acid led to a significantly higher degree of demineralization than did the $15 \mathrm{~s}$ application of tin-chloride, despite a $\mathrm{pH}$ similar to

Table 3 Failure mode

\begin{tabular}{|c|c|c|c|c|c|}
\hline \multirow[t]{2}{*}{ Groups ( $\mathrm{n}=22$ molars per group) } & \multicolumn{5}{|c|}{ Failure mode ( 4 beams per molar $=88$ beams per group $)$} \\
\hline & $\begin{array}{l}\text { Cohesive failure } \\
\text { in dentin }(\%)\end{array}$ & $\begin{array}{l}\text { Adhesive failure } \\
\text { at dentin-adhesive } \\
\text { interface }(\%)\end{array}$ & $\begin{array}{l}\text { Adhesive failure at } \\
\text { adhesive-resin } \\
\text { composite interface (\%) }\end{array}$ & $\begin{array}{l}\text { Mixed adhesive } \\
\text { failure }(\%)\end{array}$ & $\begin{array}{l}\text { Cohesive failure } \\
\text { in resin } \\
\text { composite }(\%)\end{array}$ \\
\hline Group $1\left(\mathrm{H}_{3} \mathrm{PO}_{4}+\right.$ Optibond FL) & 0 & 1 & 4 & 27 & 68 \\
\hline Group $2\left(\mathrm{SnCl}_{2}+\right.$ Optibond FL $)$ & 0 & 53 & 9 & 31 & 7 \\
\hline Group $3\left(\mathrm{H}_{3} \mathrm{PO}_{4}+\mathrm{SnCl}_{2}+\right.$ Optibond FL $)$ & 0 & 7 & 0 & 42 & 51 \\
\hline Group 4 (Clearfil SE) & 3 & 5 & 14 & 36 & 42 \\
\hline Group $5\left(\mathrm{H}_{3} \mathrm{PO}_{4}+\right.$ Clearfil SE $)$ & 0 & 2 & 12 & 31 & 55 \\
\hline Group $6\left(\mathrm{SnCl}_{2}+\right.$ Clearfil SE $)$ & 0 & 0 & 5 & 17 & 78 \\
\hline
\end{tabular}


Fig. 2 Micrographs of the scanning electron microscopy (SEM) for qualitative evaluation of dentin surfaces of the groups tested

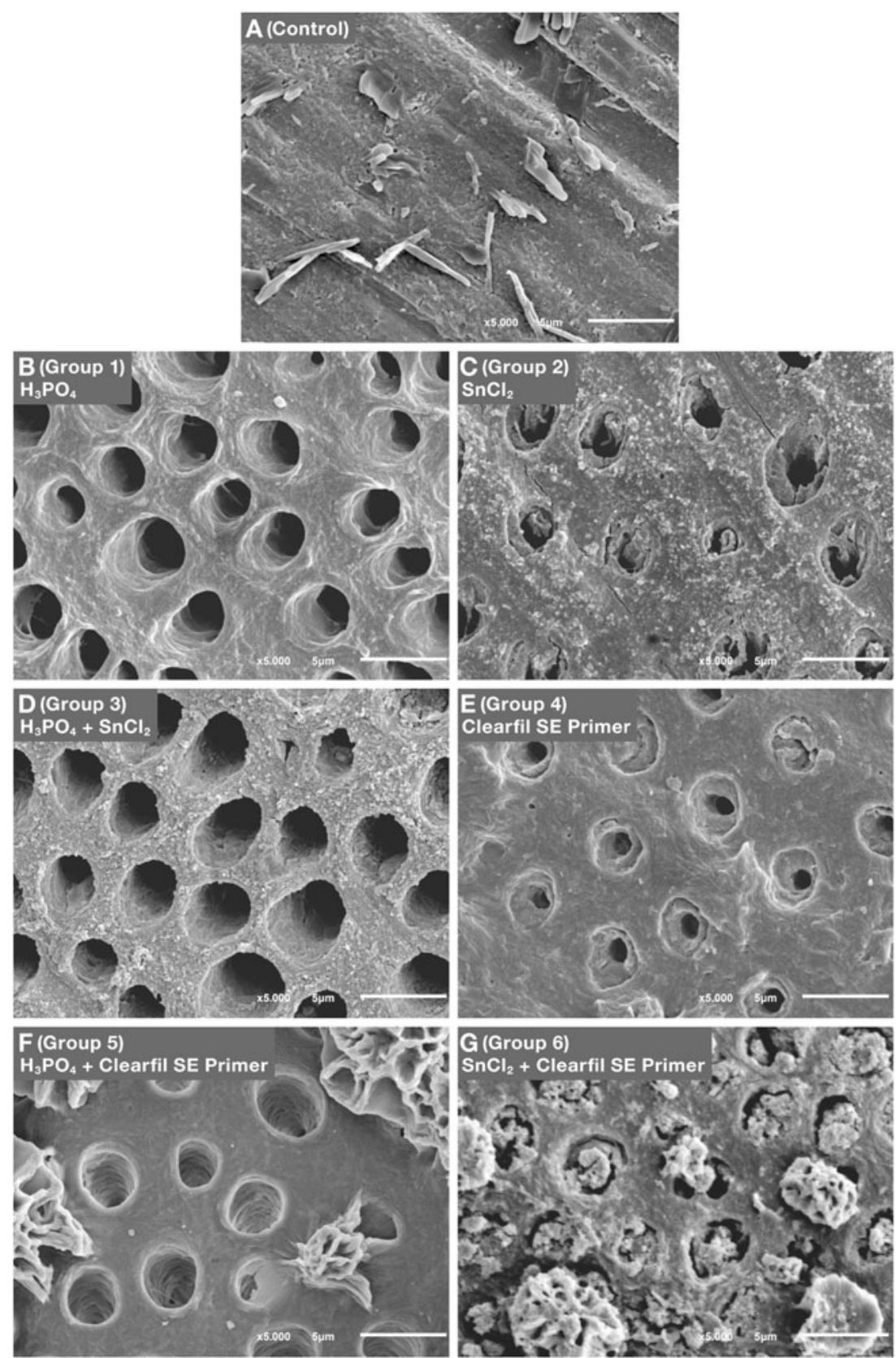

that of phosphoric acid. A scaffold of collagen fibrils nearly totally depleted of hydroxyapatite allowing for effective penetration of first the primer (Optibond FL Prime) and then the adhesive/bond (Optibond FL Adhesive) into the interfibrillar spaces of the collagen network and into the dentin tubules most probably account for the superior bonding performance obtained via phosphoric acid etching. These bond strength results are corroborated by the failure mode observations: Whereas cohesive failure in resin composite was the most common failure mode when the dentin had been pretreated with phosphoric acid, adhesive failure was the most common failure mode when the dentin had been pretreated with tin-chloride.
The fact that the pretreatment involving a $7 \mathrm{~s}$ application of phosphoric acid followed by a $7 \mathrm{~s}$ application of tin-chloride (Table 1) gave a bond strength result with Optibond FL that lay in between those of the two other groups implies that dentin demineralization was of paramount importance and that presence of tin precipitations had a negative effect on the bond promoting capacity of Optibond FL.

As all self-etch adhesive systems, Clearfil SE, the so-called gold standard of two-step self-etch adhesive systems, simultaneously etches and primes the dentin upon application of the primer component leading to partial dissolution of the smear layer and demineralization of the underlying dentin and to micro-mechanical bonding via a relatively thin hybrid layer 
Fig. 3 Spectra of the energy dispersive X-ray spectroscopy (EDX) for qualitative

evaluation of dentin surfaces of the groups tested
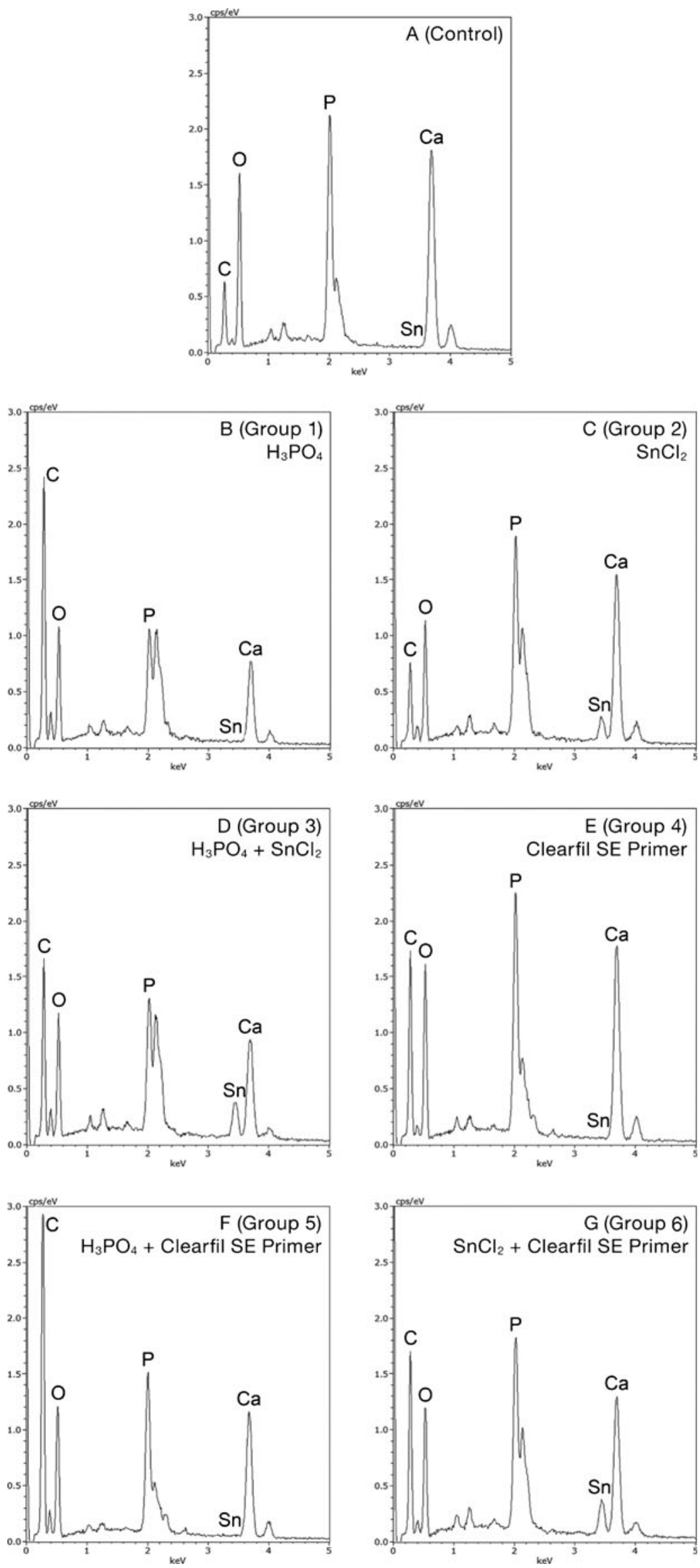
$(0.5-1 \mu \mathrm{m})[14,15]$. In corroboration with previously published results [15-17], the SEM micrographs and the EDX results showed that application of the Clearfil SE Primer led to less demineralization of the dentin than did phosphoric acid etching. The incomplete demineralization, resulting from the relative mildness $(\mathrm{pH} \approx 2)$ of the primer [18], leaves substantial amounts of hydroxyapatite crystals around the collagen fibrils. It has been shown that calcium ions released during the partial dissolution of hydroxyapatite diffuse within the hybrid layer and join together MDP molecules in nano-layers $[19,20]$, the process being driven by the formation of MDP-calcium salts. The low solubility of these salts and the hydrophobicity of the nano-layered structure is believed to render the hybrid layer less prone to hydrolytic degradation and thus to increase the stability of the bond [16, 20,21].

The introduction of a phosphoric acid etching step prior to application of the Clearfil SE Primer had no significant effect on the bond strength. This finding is at odds with the results of previously published studies in which bond strength was reduced as a consequence of phosphoric acid etching [15, 22]. The negative effect was explained by inferior quality of the hybrid layer caused by incomplete infiltration of the demineralized collagen network by the bonding resin [22, 23] and lack of chemical interaction between MDP and hydroxyapatite [15].

In contrast, the introduction of a tin-chloride pretreatment step prior to application of the Clearfil SE Primer led to an increase in bond strength as compared to the standard procedure despite more pronounced removal of smear layer and more pronounced demineralization as revealed by SEM and EDX. Several possible modes of interaction of the tin ions present in the tin precipitates have been proposed [12]. The fact that the tin-chloride pretreament had a negative effect on the performance of Optibond FL, but a favorable effect on the performance of Clearfil SE leads to rejection of the null hypothesis and also suggests that the bond-promoting effect is linked to the presence of MDP. This lends support to the theory that tin ions function in the same manner as does calcium in the MDP-calcium salt to promote "docking" of MDP to collagen. Tin ions linked to free collagen sites are obviously bound to MDP thereby enhancing adhesion. Such an action mode would also explain the superior adhesion performance of Clearfil SE on erosively altered dentin with no calcium present in the hybrid layer [12]. Our hypothesis that tin binds to collagen and with MDP forms an MDP-tin salt leading to additional docking sites for MDP should be the aim of further research.

\section{Conclusion}

Whereas partial or total replacement of phosphoric acid etching with tin-chloride pretreatment had a negative effect on the bond-promoting capacity of a three-step etch-and-rinse adhesive, inclusion of a tin-chloride pretreatment had a beneficial influence on the resin composite to dentin bond strength mediated by an MDP-containing adhesive system.

Acknowledgments The authors would like to thank Gaba International AG, Therwil, Switzerland and Kuraray Europe, Germany for providing the materials needed. Furthermore, we thank J. Wandel and Prof. Dr. J. Hüsler, Institute of Mathematical Statistics and Actuarial Science, University of Bern for statistical analyses.

Conflicts of interest The authors declare no conflicts of interest, real or perceived, financial or non-financial.

\section{References}

1. Van Loveren C (1990) The antimicrobial action of fluoride and its role in caries inhibition. J Dent Res 69:676-683, Special No

2. Van Loveren C (2001) Antimicrobial activity of fluoride and its in vivo importance: identification of research questions. Caries Res 35(Suppl. 1):65-70

3. Miller S, Truong T, Heu R, Stranick M, Bouchard D, Gaffar A (1994) Recent advances in stannous fluoride technology: antibacterial efficacy and mechanism of action towards hypersensitivity. Int Dent J 44:83-94

4. Paraskevas S, van der Weijden GA (2006) A review of the effects of stannous fluoride on gingivitis. J Clin Periodontol 33:1-13

5. Ganss C, Neutard L, von Hinckeldey J, Kilmek J, Schlueter N (2010) Efficacy of a tin/fluoride rinse: a randomized in situ trial on erosion. J Dent Res 89:1214-1218

6. Ganss C, Schlueter N, Hardt M, Schattenberg P, Klimek J (2008) Effect of fluoride compounds on enamel erosion in vitro: a comparison of amine, sodium and stannous fluoride. Caries Res 42:2-7

7. Ganss C, Lussi A, Sommer N, Klimik J, Schlueter N (2010) Efficacy of fluoride compounds and stannous chloride as erosion inhibitors in dentine. Caries Res 44:248-252

8. Ganss C, Lussi A, Grunau O, Klimek J, Schlueter N (2011) Conventional and anti-erosion fluoride toothpastes: effect on enamel erosion and erosion-abrasion. Caries Res 45:581-589

9. Huysmans MCDNJM, Jager DHJ, Ruben JL, Unk DEMF, Klijn CPAH, Vieira AM (2011) Reduction of erosive wear in situ by stannous fluoride-containing toothpaste. Caries Res 45:518-523

10. Schlueter N, Klimek J, Ganss C (2009) Efficacy of an experimental tin-F-containing solution in erosive tissue loss in enamel and dentine in situ. Caries Res 43:415-421

11. Ganss C, Hardt M, Lussi A, Cocks AK, Klimek J, Schlueter N (2010) Mechanism of action of tin-containing fluoride solutions as anti-erosive agents in dentine - an in vitro tin-uptake, tissue loss, and scanning electron microscopy study. Eur J Oral Sci 118:376384

12. Flury S, Koch T, Peutzfeldt A, Lussi A, Ganss C (2013) The effect of a tin-containing fluoride mouth rinse on the bond between resin composite and erosively demineralised dentin. Clin Oral Invest $17: 217-225$

13. Lussi A (2006) Erosive tooth wear - a multifactorial condition of growing concern and increasing knowledge. Monogr Oral Sci 20:1-8

14. Tay FR, Sano H, Carvalho R, Pashley EL, Pashley DH (2000) An ultrastructural study of the influence of acidity of self-etching 
primers and smear layer thickness on bonding to intact dentin. $\mathrm{J}$ Adhes Dent 2:83-98

15. Van Landuyt KL, Kanumilli P, de Munck J, Peumans M, Lambrechts P, van Meerbeek B (2006) Bond strength of a mild self-etch adhesive with and without prior acid-etching. J Dent 34:77-85

16. Yoshida Y, Nagakane K, Fukuda R, Nakayama Y, Okazaki M, Shintani H, Inoue S, Tagawa Y, Suzuki K, de Munck J, van Meerbeek B (2004) Comparative study on adhesive performance of functional monomers. J Dent Res 83:454-458

17. van Meerbeek B, de Munck J, Yoshida Y, Inoue S, Vargas M, Vijay P, van Landuyt K, Lambrechts P, Vanherle G (2003) Buonocore memorial lecture. Adhesion to enamel and dentin: current status and future challenges. Oper Dent 28:215-235

18. de Munck J, Vargas M, Iracki J, van Landuyt K, Poitevin A, Lambrechts P, van Meerbeek B (2005) One-day bonding effectiveness of new self-etch adhesives to bur-cut enamel and dentin. Oper Dent 30:39-49
19. Fukegawa D, Hayakawa S, Yoshida Y, Suzuki K, Osaka A, van Meerbeek B (2006) Chemical interaction of phosphoric acid ester with hydroxyapatite. J Dent Res 85:941-944

20. Yoshiraha K, Yoshida Y, Nagaoka N, Fukegawa D, Hayakawa S, Mine A, Nakamura M, Minagi S, Osaka A, Suzuki K, van Meerbeek B (2010) Nano-controlled molecular interaction at adhesive interfaces for hard tissue reconstruction. Acta Biomater 6:3573-3582

21. Yoshida Y, Yoshihara K, Nagaoka N, Hayakawa S, Torii Y, Ogawa T, Osaka A, van Meerbeek B (2012) Self-assembled nano-layering at the adhesive interface. J Dent Res 91:376-381

22. Torii Y, Itou K, Nishitani Y, Ishikawa K, Suzuki K (2002) Effect of phosphoric acid etching prior to self-etching primer application on adhesion of resin composite to enamel and dentin. Am J Dent 15:305-308

23. Walker MP, Wang Y, Swafford J, Evans A, Spencer P (2000) Influence of additional acid etch treatment on resin cement dentin infiltration. J Prosthod 9:77-81 